\begin{tabular}{|l|}
\hline Access this article online \\
\hline Quick Response Code: \\
\hline
\end{tabular}

Departments of Laboratory Medicine and ${ }^{1}$ Surgery, Jai Prakash Narayan Apex Trauma Centre, All India Institute of Medical Sciences, ${ }^{2}$ Department of Orthopedics, All India Institute of Medical Sciences, New Delhi, India

Address for correspondence:

Dr. Purva Mathur,

Department of Laboratory Medicine, Jai Prakash Narayan Apex Trauma Centre, All India Institute of Medical Sciences, New Delhi - 110 029, India.

E-mail: purvamathur@ yahoo.co.in

Submission: 09-06-2018 Accepted: 30-08-2018

\section{Pattern of antimicrobial resistance of Gram-negative bacilli in surgical site infections in in-patients and out-patients at an apex trauma Center: 2013-2016}

\author{
Nidhi Bhardwaj, Surbhi Khurana, Minu Kumari', Rajesh Malhotra², Purva Mathur
}

\begin{abstract}
:
INTRODUCTION: Antimicrobial resistance is an increasing problem worldwide especially among the surgical site infections (SSIs). SSI is becoming more serious due to hospital-acquired infections/nosocomial infections, which further leads to the overuse of broad-spectrum antibiotics. To investigate the antimicrobial resistance patterns among Gram-negative bacteria in SSI in in- and out-patients the present study was designed.
\end{abstract}

METHODOLOGY: During the 4 years (January 2013-December 2016), the antimicrobial resistant pattern was studied in the admitted patients and in the patients who were followed up to the outpatients department (OPD) after discharge. Antimicrobial resistance pattern testing was done by the disk diffusion method on Mueller-Hinton agar and by E-test for ten antibiotics according to The Clinical and Laboratory Standards Institute guidelines for Gram-negative bacilli.

RESULTS: A total of 2,447 strains were isolated from the studied population on over the period of 4 years. Of 2447, 1996 (81\%) were isolated from patients who had SSI during the hospital stay, and 451 (18\%) were from patients who attended the OPD after discharge. In the outpatients, who followed up in the OPD for the SSI, Escherichia coli (148), and Pseudomonas aeruginosa (93), whereas in the patients who develop SSI during their hospital stay, Acinetobacter baumannii (622), E. coli (424), and Klebsiella pneumoniae (315) were found to be common. A very high resistance pattern was observed in both the studied groups; however, a higher resistance pattern was seen in in-patients as compared to outpatients.

CONCLUSION: In our study, we have reported resistance pattern in Gram-negative bacteria isolated from the patients who were came for the follow as well as in the inpatients. For the outpatients, it can be concluded that it could be a community-acquired infection which is also an alarming condition for our society.

Key words:

Antimicrobial resistant, in- and out-patients, surgical site infections

\section{Introduction}

ntimicrobial resistance is an increasing Aproblem worldwide especially among the surgical site infections (SSIs). SSI is becoming more serious due to

This is an open access journal, and articles are distributed under the terms of the Creative Commons Attribution-NonCommercial-ShareAlike 4.0 License, which allows others to remix, tweak, and build upon the work non-commercially, as long as appropriate credit is given and the new creations are licensed under the identical terms.

For reprints contact: reprints@medknow.com hospital-acquired infections/nosocomial infections. ${ }^{[1,2]}$ Hospital-acquired infections are increasing day-by-day because of the severity of illness, length of Intensive Care Unit (ICU) stay, and usage of invasive devices and procedures. ${ }^{[3-5]}$ These infections have been reported to affect approximately 2 million hospitalized patients in the US

How to cite this article: Bhardwaj N, Khurana S, Kumari M, Malhotra R, Mathur P. Pattern of antimicrobial resistance of Gram-negative bacilli in surgical site infections in in-patients and out-patients at an apex trauma center: 2013-2016. J Lab Physicians 2018;10:432-6. 
annually and have imposed 57.6 billion dollars in expense to the US health system in 2000. ${ }^{[4,6,7]}$ Patients after surgery are at risk of acquiring hospital-acquired infections which further contributes to higher rates of surgical site rates. A large number of nosocomial infection leads to SSI. SSIs further results in the overuse of broad-spectrum antibiotics. Frequent rational use of these antibiotics results in the resistant to antimicrobial drugs among which high resistant are seen in Gram-negative bacteria. The resistance further leads to serious infections among which SSIs are the most common. ${ }^{[8]}$ Antimicrobial resistance is spreading rapidly among the bacterial population which further made the treatment difficult and challenging especially in surgical and clinical practice ${ }^{\left[{ }^{[9]}\right.}$ SSI are still remains the major problem in clinical practices and further considering the high level of resistance pattern in SSI patients, ${ }^{[1,10]}$ it is becoming important to identify the resistant pattern among these SSI cases. Most of the studies were evaluated the resistance pattern of the organisms in SSI cases till the hospital stay only but as most of the infections emerges after the discharge which could be community acquired once the patient was discharged from the hospital. It is very important to establish a resistance pattern of SSI in hospital-acquired or community-acquired infections.

To keep this in mind, the present study was designed to investigate the antimicrobial resistance patterns among Gram-negative bacteria in SSIs in in- and out-patients.

\section{Case History}

During a 4-year study, from January 2013 to December 2016, we studied pattern of antimicrobial resistance in SSI from outpatients and inpatients, received in the clinical microbiology laboratories.

\section{Bacterial isolates}

The Gram-negative bacilli in this study were recovered from clinical samples of SSI from our hospital and patients population was divided into two groups: in- and out-patients.

\section{Inpatients}

Gram-negative bacilli were isolated from the patients who develop SSI after the surgery and Pus/wound sample was collected from the surgical site.

\section{Outpatients}

Patients after surgery were followed up after discharge, and sample was collected when patients attended the OPD for follow-up. Gram-negative isolates were identified by standard microbiological methods.

The identification was confirmed for all isolates by the Vitek 2 identification cards (Biomerix, France). All the strains were stocked at $-70^{\circ} \mathrm{C}$ for further analysis in stocking beads (Microbank, Pro-Lab Diagnostics, and Richmond Hill, Canada).

\section{Antimicrobial susceptibility testing}

The antimicrobial susceptibility testing of Gram-negative was performed by the disk diffusion method on Mueller-Hinton agar according to the recommendations of the Clinical and Laboratory Standards Institute (CLSI). The following antibiotics were tested: Amikacin (AMK) $(30 \mu \mathrm{g})$, Cefepime (CFPM) $(30 \mu \mathrm{g})$, Cefoperazone/Sulbactam (CPZ/SUL) $(75 / 30 \mu \mathrm{g})$, Ceftazidime (CAZ) $(30 \mu \mathrm{g})$, Chloramphenicol (CAM) $(30 \mu \mathrm{g})$, Ciprofloxacin (CIP) $(5 \mu \mathrm{g})$, Imipenem (IPM) $(10 \mu \mathrm{g})$, Netilmycin (NET) $(30 \mu \mathrm{g})$, Piperacillin/Tazobactam (PIT) $(100 \mu \mathrm{g} / 10 \mu \mathrm{g})$, and Tigecycline (TGC) $(15 \mu \mathrm{g})$. The MIC was determined by E-test for all the above antimicrobials; performed according to manufacturer's recommendations (Biomeriux Ltd., formerly AB Biodisk, Sweden). The inhibition zone diameters and MIC breakpoints were adopted according to CLSI guidelines for Gram-negative bacilli.

\section{Results}

A total of 2447 strains were isolated from the studied population over the period of 4 years. Of $2447,1996(81 \%)$ were isolated from patients who had SSI during the hospital stay, and $451(18 \%)$ were from patients who attended the outpatients department (OPD) after discharge. In the outpatients, who followed up in the OPD for the SSI, Escherichia coli (148) and Pseudomonas aeruginosa (93) were observed to be the most common isolate followed by Klebsiella pneumoniae (58), Acinetobacter baumannii (49), Enterobacter cloacae (42), and Proteus mirabilis (40), whereas in the patients who develop SSI during their hospital stay, A. baumannii (622), E. coli (424) and $K$. pneumoniae (315) were found to be commonly followed by P. aeruginosa (298), E. cloacae (137) during 2013-2016. All the organisms were isolated from pus and wound. Distribution of Gram-negative organisms during the study period is shown in Table 1.

Antimicrobial Resistance patterns of Gram-negative bacteria in surgical site infections resistance pattern in outpatients

A high level of the resistant pattern was observed in the patients who were followed up for the SSI after discharge. The highest resistance by A. baumannii was seen followed by K. pneumonia, E. coli and P. aeruginosa against AMK, CFPM, CPZ/SUL, CAZ, CAM, CIP, IPM, NET, and PIT. Resistance to TGC was least in all organisms isolated from a sample taken from OPD patients. Only $P$. aeruginosas showed high resistance in TGC. Among 
the isolates obtained from the OPD patient A. baumannii, E. cloacae, K. pneumonia, E. coli and P. aeruginosa shown a very high resistance to above-mentioned antibiotics. The detailed resistant pattern of these organisms are shown in Table 2.

\section{Resistance pattern in inpatients}

As compared to the outpatient population, inpatients population showed a high number of organisms isolated from the surgical site and very high resistance was seen in this group of the population. Among the total isolated (1996) obtained from inpatients A. baumannii,
Aeromonas hydrophilla, Citrobacter fruendii, E. cloacae, E. coli, K. pneumoniae, Morganella morganii, P. mirabilis, Providencia stuartii, and P. aeruginosa were found to be common isolates and showed high resistance among these organism. A. baumannii showed $97 \%$ resistance to CAZ and CFPM (Cefepime); $95 \%$ to PIT; $94 \%$ and $91 \%$ to AMK and CAM, respectively. Similar high resistance by E. coli for CIP (92\%) and CAZ (90\%); K.pneumoniae showed $88 \%$ resistance to CAZ, $85 \%$ to CEPM, $81 \%$ to NET and CIP; P. aeruginosa showed $89 \%$ resistance to CAM. The detailed resistant pattern of these organisms is shown in Table 3.

Table 1: Distribution of organisms over the period of 4 years

\begin{tabular}{|c|c|c|c|c|c|c|c|c|c|}
\hline & \multicolumn{2}{|c|}{2013} & \multicolumn{2}{|c|}{2014} & \multicolumn{2}{|c|}{2015} & \multicolumn{2}{|c|}{2016} & \multirow[t]{2}{*}{ Total } \\
\hline & $\begin{array}{c}\text { Out } \\
\text { patients, } \\
n(\%)\end{array}$ & $\begin{array}{c}\text { In patients, } \\
n(\%)\end{array}$ & $\begin{array}{c}\text { Out } \\
\text { patients, } \\
n(\%)\end{array}$ & $\begin{array}{c}\text { In patients, } \\
n(\%)\end{array}$ & $\begin{array}{c}\text { Out } \\
\text { patients, } \\
n(\%)\end{array}$ & $\begin{array}{c}\text { In patients, } \\
n(\%)\end{array}$ & $\begin{array}{c}\text { Out } \\
\text { patients, } \\
n(\%)\end{array}$ & $\begin{array}{c}\text { In patients, } \\
n(\%)\end{array}$ & \\
\hline Acinetobacter baumannii & $15(11)$ & $21(3)$ & $15(12)$ & $162(34)$ & $5(6)$ & $108(31)$ & $14(11)$ & $141(28)$ & 481 \\
\hline Acinetobacter Iwoffii & - & $3(0.4)$ & $1(0.8)$ & $2(0.4)$ & & $3(1)$ & & 1 & 10 \\
\hline Aeromonas hydrophilla & $1(1)$ & $13(2)$ & & $9(2)$ & & & & 1 & 24 \\
\hline Citrobacter amalonaticus & - & - & - & - & - & - & $1(0.8)$ & - & 1 \\
\hline Citrobacter fruendii & - & $4(2)$ & $1(0.8)$ & $7(1.4)$ & $2(2.5)$ & $3(1)$ & - & $15(3)$ & 32 \\
\hline Citrobacter koseri & - & - & $2(1)$ & $2(0.4)$ & - & - & - & $3(0.7)$ & 7 \\
\hline Enterobacter aerogenes & $3(2)$ & 1 & & & & & $1(0.8)$ & $4(0.7)$ & 9 \\
\hline Enterobacter cloacae & 17 & $56(8)$ & $6(5)$ & $24(5)$ & $8(10)$ & $37(10)$ & $11(9)$ & $20(4)$ & 179 \\
\hline Enterobacter gergoviae & - & - & - & 1 & - & - & - & - & 1 \\
\hline Escherichia coli & $42(31)$ & $125(18)$ & $43(36)$ & $91(19)$ & $26(32)$ & $90(26)$ & $37(31)$ & $118(23)$ & 572 \\
\hline Klebsiella pneumoniae & $14(10)$ & $118(17)$ & $18(15)$ & $60(12)$ & $8(10)$ & $40(12)$ & $18(15)$ & $97(19)$ & 373 \\
\hline Morganella morganii & & 1 & & $7(1.5)$ & & $2(0.5)$ & & 1 & 11 \\
\hline Proteus mirabilis & $14(10)$ & $34(5)$ & $8(7)$ & $13(2)$ & $11(14)$ & $14(4)$ & $7(6)$ & $23(4.5)$ & 124 \\
\hline Providencia rettgeri & - & - & $1(0.8)$ & - & $1(1.25)$ & - & - & 1 & 3 \\
\hline Providencia stuartii & - & $13(2)$ & $1(0.8)$ & 1 & - & - & $2(1.6)$ & - & 17 \\
\hline Pseudomonas aeruginosa & $28(20)$ & $81(12)$ & $19(16)$ & $88(18)$ & $19(23)$ & $49(14)$ & $27(22)$ & $80(16)$ & 391 \\
\hline Pseudomonas luteola & - & 2 & - & 1 & - & - & $1(0.8)$ & - & 4 \\
\hline Pseudomonas putida & - & $3(0.4)$ & - & - & - & 1 & - & - & 4 \\
\hline Pseudomonas stutzeri & - & 1 & - & - & - & - & - & - & 1 \\
\hline Serratia fonticala & - & 1 & $1(0.8)$ & - & - & - & - & - & 2 \\
\hline Serratia marcescens & - & $6(10.8)$ & $1(0.8)$ & 1 & - & - & - & $2(0.3)$ & 10 \\
\hline $\begin{array}{l}\text { Sphingomonas } \\
\text { paucimobillis }\end{array}$ & - & - & - & - & - & - & $1(0.8)$ & - & 1 \\
\hline Total & 134 & 673 & 117 & 469 & 80 & 347 & 120 & 507 & 2447 \\
\hline
\end{tabular}

Table 2: Antimicrobial resistant pattern of Gram-negative bacteria isolated from surgical site infection of outpatients

\begin{tabular}{|c|c|c|c|c|c|c|c|c|c|c|}
\hline Organisms (n) & AMK, $n(\%)$ & $\begin{array}{l}\text { CFPM, } \\
n(\%)\end{array}$ & $\begin{array}{c}\text { CPZISUL, } \\
n(\%)\end{array}$ & CAZ, $n(\%)$ & CAM, $n(\%)$ & CIP, $n(\%)$ & IPM, $n(\%)$ & NET, $n(\%)$ & PIT, $n$ (\%) & TGC, $n(\%)$ \\
\hline $\begin{array}{l}\text { Acinetobacter } \\
\text { baumannii (49) }\end{array}$ & $38(78)$ & $40(82)$ & $28(57)$ & $37(76)$ & $39(80)$ & $38(78)$ & $3(67)$ & $27(55)$ & $35(71)$ & $6(12)$ \\
\hline $\begin{array}{l}\text { Enterobacter } \\
\text { cloacae (42) }\end{array}$ & $17(40)$ & $11(26)$ & $12(29)$ & $16(38)$ & $9(21)$ & $11(26)$ & $23(55)$ & $12(29)$ & $12(29)$ & $4(10)$ \\
\hline Escherichia coli (148) & $23(16)$ & $107(22)$ & $52(35)$ & $112(76)$ & $21(14)$ & $97(66)$ & $10(7)$ & $26(18)$ & $47(32)$ & $4(3)$ \\
\hline $\begin{array}{l}\text { Klebsiella } \\
\text { pneumoniae (58) }\end{array}$ & $29(50)$ & $34(59)$ & $32(55)$ & $39(67)$ & $30(52)$ & $35(60)$ & $15(26)$ & $33(57)$ & $31(53)$ & $9(16)$ \\
\hline Proteus mirabilis (40) & $17(43)$ & $19(48)$ & $6(15)$ & $27(68)$ & $23(58)$ & $22(55)$ & $10(25)$ & $15(38)$ & $2(5)$ & $21(53)$ \\
\hline $\begin{array}{l}\text { Pseudomonas } \\
\text { aeruginosa (93) }\end{array}$ & $38(41)$ & $32(34)$ & $22(24)$ & $40(43)$ & $69(74)$ & $37(40)$ & $23(25)$ & $31(33)$ & 0 & $77(83)$ \\
\hline
\end{tabular}

AMK = Amikacin, CFPM = Cefepime, CPZ/SUL = Cefoperazone/sulbactam, CAZ = Ceftazidime, CAM = Chloramphenicol, CIP = Ciprofloxacin, IPM = Imipenem, NET = Netilmycin, PIT = Piperacillin/tazobactam, TGC $=$ Tigecycline 
Table 3: Antimicrobial resistant pattern of Gram-negative bacteria isolated from surgical site infection of inpatients

\begin{tabular}{|c|c|c|c|c|c|c|c|c|c|c|}
\hline Organisms $(n)$ & $\begin{array}{l}\text { AMK, } \\
n(\%)\end{array}$ & $\begin{array}{c}\text { CFPM, } \\
n(\%)\end{array}$ & $\begin{array}{c}\text { CPZ/SUL, } \\
n(\%)\end{array}$ & $\begin{array}{l}\text { CAZ, } \\
n(\%)\end{array}$ & $\begin{array}{l}\text { CAM, } \\
n(\%)\end{array}$ & CIP, $n(\%)$ & IPM, $n(\%)$ & $\begin{array}{l}\text { NET, } \\
n(\%)\end{array}$ & PIT, $n(\%)$ & $\begin{array}{l}\text { TGC, } \\
n(\%)\end{array}$ \\
\hline Acinetobacter baumannii (622) & $584(94)$ & $603(97)$ & $546(88)$ & $601(97)$ & $568(91)$ & $485(78)$ & $574(92)$ & $386(62)$ & $594(95)$ & $138(22)$ \\
\hline Aeromonas hydrophilla (23) & $9(39)$ & & $21(91)$ & $18(78)$ & $23(100)$ & $16(70)$ & $9(39)$ & $5(22)$ & $15(65)$ & \\
\hline Citrobacter fruendii (29) & $14(48)$ & $19(66)$ & $21(72)$ & $23(79)$ & $15(52)$ & $15(52)$ & $7(24)$ & $15(52)$ & $15(52)$ & $3(10)$ \\
\hline Enterobacter cloacae (137) & $70(51)$ & $80(58)$ & $78(57)$ & $93(68)$ & $46(34)$ & 7 (53) 3 & $45(33)$ & $88(64)$ & $74(54)$ & $7(5)$ \\
\hline Escherichia coli (424) & $124(29)$ & $346(82)$ & $204(48)$ & $380(90)$ & $118(28)$ & $390(92)$ & $80(19)$ & $149(35)$ & $243(57)$ & $7(2)$ \\
\hline Klebsiella pneumoniae (315) & $222(70)$ & $267(85)$ & $241(77)$ & $277(88)$ & $162(51)$ & $255(81)$ & $169(54)$ & $254(81)$ & $240(76)$ & $39(12)$ \\
\hline Morganella morganii (11) & $6(55)$ & $5(45)$ & $6(55)$ & $8(73)$ & $6(55)$ & $8(73)$ & $8(73)$ & $6(55)$ & $5(45)$ & $4(36)$ \\
\hline Proteus mirabilis (84) & $34(40)$ & $58(69)$ & $17(20)$ & $65(77)$ & $42(50)$ & $54(64)$ & $19(23)$ & $62(74)$ & $9(11)$ & $63(75)$ \\
\hline Providencia stuartii (16) & $7(44)$ & $7(44)$ & $9(56)$ & $9(56)$ & $10(63)$ & $9(56)$ & $2(13)$ & $7(44)$ & $5(31)$ & $13(81)$ \\
\hline Pseudomonas aeruginosa (298) & $156(52)$ & $175(59)$ & $195(65)$ & $184(62)$ & $265(89)$ & $190(64)$ & $158(53)$ & $185(62)$ & $3(1)$ & $197(66)$ \\
\hline
\end{tabular}

AMK = Amikacin, CFPM = Cefepime, CPZ/SUL = Cefoperazone/sulbactam, CAZ = Ceftazidime, CAM = Chloramphenicol, CIP = Ciprofloxacin, IPM = Imipenem, NET = Netilmycin, PIT = Piperacillin/tazobactam, TGC = Tigecycline

\section{Discussion}

Antimicrobial resistance in surgical sites is emerging problem worldwide, which further result in increased hospital stay of the patients and mortality. SSI is the most common problem in hospital after surgery further increasing resistance to the antibiotics are of major concern. In the present study, resistance pattern was studied in SSI patients. ${ }^{[8-10]} \mathrm{A}$ total of 451 isolates were found in the patients who had SSI after discharge, and a very high number of SSI isolates $(n=1996)$ were reported in the admitted patients. Similarly, we have reported the difference in antibiotic-resistant in SSI group of patients. In the present study, A. baumannii, C. fruendii, E. cloacae, E. coli, K. pneumoniae, P. mirabilis, Providencia stuartii, and $P$. aeruginosa showed high resistance to most of the antibiotics tested in the study; $A$. baumannii showed $97 \%$ resistance to CAZ and CEPM; $95 \%$ to PIT; $94 \%$ and $91 \%$ to AMK and CAM, respectively whereas in the outpatients Acinetobacter baumannii showed $76 \%$ resistance to CAZ and $82 \%$ to CEPM; $71 \%$ to PIT; $71 \%$ and $80 \%$ to AMK and CAM, respectively. Similarly, high resistance by E. coli for CIP (92\%) and CAZ (90\%); K. pneumoniae showed $88 \%$ resistance to CAZ, $85 \%$ to CEPM, $81 \%$ to NET and CIP; P. aeruginosa showed 89\% resistance to CAM. Whereas, in outpatients, E. coli for CIP (66\%) and CAZ (76\%); K. pneumoniae showed 67\% resistance to CAZ, 59\% to CEPM, 57\% to NET, and $60 \%$ to CIP; $P$. aeruginosa showed $74 \%$ resistance to CAM.

Increasing pattern in antimicrobial drugs are increasing worldwide in a study published in 2016 by published in 2016 by Krunal Shah reported decreased level of IPM from $94.25 \%$ to $36.17 \%$ over the period of $2 \frac{1}{2}$ years, however in contrast to our they have reported increased level of susceptibility in AMK from 29.31\% to $40.42 \% .{ }^{[11]}$ A study by Chandra Prakash Bhatt in 2014 showed similar results for Gram-negative isolates on SSI, Acinetobacter spp., K. pneumoniae, E. coli, and P. aeruginosa and they have also reported a high level of resistance to the antibiotics tested in the study. ${ }^{[12]}$ They have found $73.91 \%$ resistance to $\mathrm{CIP}$, but in contrast, they have found AMK sensitive to Gram-negative bacteria. Raza et al. ${ }^{[12]}$ showed that $96 / 120(80 \%)$ sample was culture positive out of them $58.33 \%$ were Gram-negative bacilli. ${ }^{[13]}$ A very high level of resistance was observed in the admitted patients, especially in ICU patients who are due to nosocomial infection by another study. ${ }^{[14]}$ Antimicrobial resistance pattern for SSI patients for each hospital is important for the appropriate treatment of the patients and to control the nosocomial infection in the hospital setting.

\section{Conclusion}

In our study, we have reported resistance pattern in Gram-negative bacteria isolated from the patients who were came for the follow, so it can be concluded that it could be a community-acquired infection which is also an alarming condition for our society. Society needs to control the commercially available antibiotics in the market. Our data suggest the high level of resistance in SSI in- and out-patients. Surveillance of SSI is important to understand the magnitude of the problem and find out appropriate preventive methods.

\section{Acknowledgment}

We would like to thank JPNA Trauma Centre, AIIMS, New Delhi, and our laboratory staff for conducting this study.

\section{Financial support and sponsorship}

Nil.

\section{Conflicts of interest}

There are no conflicts of interest.

\section{References}

1. Owens CD, Stoessel K. Surgical site infections: Epidemiology, 
microbiology and prevention. J Hosp Infect 2008;70 Suppl 2:3-10.

2. Bastola R, Parajuli P, Neupane A, Paudel A. Surgical site infections: Distribution studies of sample, outcome and antimicrobial susceptibility testing. J Med Microbiol Diagn 2017;6:2161-703.

3. Takesue Y, Kusachi S, Mikamo H, Sato J, Watanabe A, Kiyota H, et al. Antimicrobial susceptibility of pathogens isolated from surgical site infections in Japan: Comparison of data from nationwide surveillance studies conducted in 2010 and 2014-2015. J Infect Chemother 2017;23:339-48.

4. Prabhakar P, Raje D, Castle D, Rao B, Fletcher P, Duquesnay D, et al. Nosocomial surgical infections: Incidence and cost in a developing country. Am J Infect Control 1983;11:51-6.

5. Falagas ME, Bliziotis IA, Siempos II. Attributable mortality of Acinetobacter baumannii infections in critically ill patients: A systematic review of matched cohort and case-control studies. Crit Care 2006;10:R48.

6. Centers for Disease Control (CDC). Public health focus: Surveillance, prevention, and control of nosocomial infections. MMWR Morb Mortal Wkly Rep 1992;41:783-7.

7. Chaudhary R, Thapa SK, Rana JC, Shah PK. Surgical site infections and antimicrobial resistance pattern. J Nepal Health Res Counc 2017;15:120-3.

8. Saravanan R, Raveendaran V. Antimicrobial resistance pattern in a tertiary care hospital: An observational study. J Basic Clin
Pharm 2013;4:56-63.

9. Craven DE, Kunches LM, Lichtenberg DA, Kollisch NR, Barry MA, Heeren TC, et al. Nosocomial infection and fatality in medical and surgical intensive care unit patients. Arch Intern Med 1988;148:1161-8.

10. Shah K, Hemachander SS, Lakhani SJ, Khara R. Change in antibiotic sensitivity pattern of Klebsiella pneumoniae: A two and half year study. Int J Curr Microbiol Appl Sci 2016;5:549-54.

11. Bhatt CP, Baidya R, Karki P, Shah RK, Miya R, Mahashate P, et al. Multi drug resistance bacterial isolates of surgical site infection. Open J Med Microbiol 2014;4:203.

12. Raza MS, Chander A, Ranabhat A. Antimicrobial susceptibility patterns of the bacterial isolates in post-operative wound infections in a tertiary care hospital, Kathmandu, Nepal. Open J Med Microbiol 2013;3:159.

13. Pal N, Guhathakurta R, Al-Jumaily EF, Al-Mudallal NH, Muhimen NA, Al-Shaibany AA. Surgical site infection in surgery ward at a tertiary care hospital: The infection rate and the bacteriological profile. J Pharm 2012;2:1-5.

14. Ballus J, Lopez-Delgado JC, Sabater-Riera J, Perez-Fernandez XL, Betbese AJ, Roncal JA, et al. Surgical site infection in critically ill patients with secondary and tertiary peritonitis: Epidemiology, microbiology and influence in outcomes. BMC Infect Dis 2015;15:304. 